Supplement of Earth Syst. Dynam., 11, 977-993, 2020

https://doi.org/10.5194/esd-11-977-2020-supplement

(c) Author(s) 2020. This work is distributed under

the Creative Commons Attribution 4.0 License.

(c) (i)
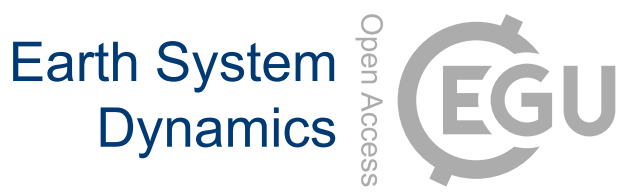

Supplement of

\title{
A continued role of short-lived climate forcers under the Shared Socioeconomic Pathways
}

Marianne T. Lund et al.

Correspondence to: Marianne T. Lund (m.t.lund@cicero.oslo.no)

The copyright of individual parts of the supplement might differ from the CC BY 4.0 License. 


\section{Section S1 Sensitivity of our results to choice of IRF}

The AGTP depends on the choice of impulse response function for $\mathrm{CO}_{2}\left(\mathrm{IRF}_{\mathrm{CO} 2}\right)$ and climate response $\left(\mathrm{IRF}_{\mathrm{T}}\right)$. To explore this sensitivity in more detail, we repeat our calculations using alternative climate and $\mathrm{CO}_{2}$ IRF combinations. Figure $\mathrm{S} 1$ show the resulting AGTPs as a function of time for $\mathrm{CO}_{2}, \mathrm{CH}_{4}$ and $\mathrm{SO}_{2}$. The largest difference is seen between results using the

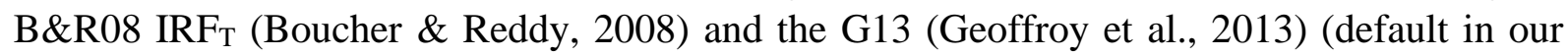
study) or G17 (Gasser et al., 2017) IRF $\mathrm{I}_{\mathrm{T}}$. Unless otherwise stated, the IRF $\mathrm{IC2}_{\mathrm{C}}$ from Joos et al. (2013) is used. The longer time scales of the climate system response in B\&R08 compared to both G13 and G17, results in an AGTP that is lower up to approx. 15 years and higher thereafter for $\mathrm{CH}_{4}$ and $\mathrm{CO}_{2}$, and stronger (i.e., more negative) for $\mathrm{SO}_{2}$ already after 5 years. Although we do not present normalized metrics here, we note that they would differ from values reported by

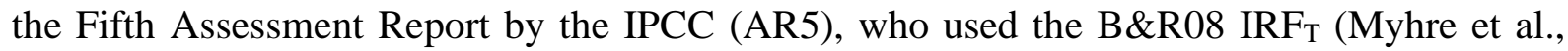
2013). As an illustration, Table S1 shows the GTP for methane for time horizons 10, 20 and 100 years (a detailed comparison for the other SLCFs is difficult due to different underlying radiative efficiencies). We also show values taken from the IPCC AR5. The difference between AR5 and values calculated using the B\&R08 IRF increase in the radiative efficiency of methane that we apply based on (Etminan et al., 2016). Using G13 or G17 IRF T $_{\mathrm{T}}$ results in 4-18\% lower GTPs compared to those based on B\&R08 for two short time horizons, and increased metric values on the 100 -year horizon. Using the $\mathrm{CO}_{2}$ IRF from G17 without the carbon-climate feedback included increases the methane GTP by 2, 5 and $11 \%$ for 10,20 and 100 years, respectively, compared to using the G17 IRF CO2 with carbon climate feedback. As noted by G17 this difference can be larger for shorter-lived species like $\mathrm{BC}$ and $\mathrm{SO}_{2}$.

We also investigate what the choice of IRFs mean for our global and regional near- and longterm temperature responses. Figure S2 shows the global-mean surface temperature response following global present-day emissions using results with the B\&R08, G13 and G17 IRF two latter yields similar results, while the total effect after 10 years is lower with B\&R08 due to a combination of smaller contributions from $\mathrm{CH}_{4}$ and $\mathrm{CO}_{2}$ and stronger cooling contributions. We also note that while the overall picture of regional and sectoral SLCF and $\mathrm{CO}_{2}$ contributions largely remains the same, the differences between B\&R08 and G13 are sufficiently large to affect the ranking by total net near-term temperature impact of some regions and sectors compared to our main Fig.2. For instance, stronger cooling contributions with the B\&R08 IRF reduces the net warming of the ENE sectors, moving AGR up as the sectors with the largest net temperature impact. Similarly, SAS and MDE, regions with significant cooling emissions and relatively small CO2 emissions, are moved down. The net temperature response to emissions in SAS switches from to a small net negative on the 10-year timescale. 

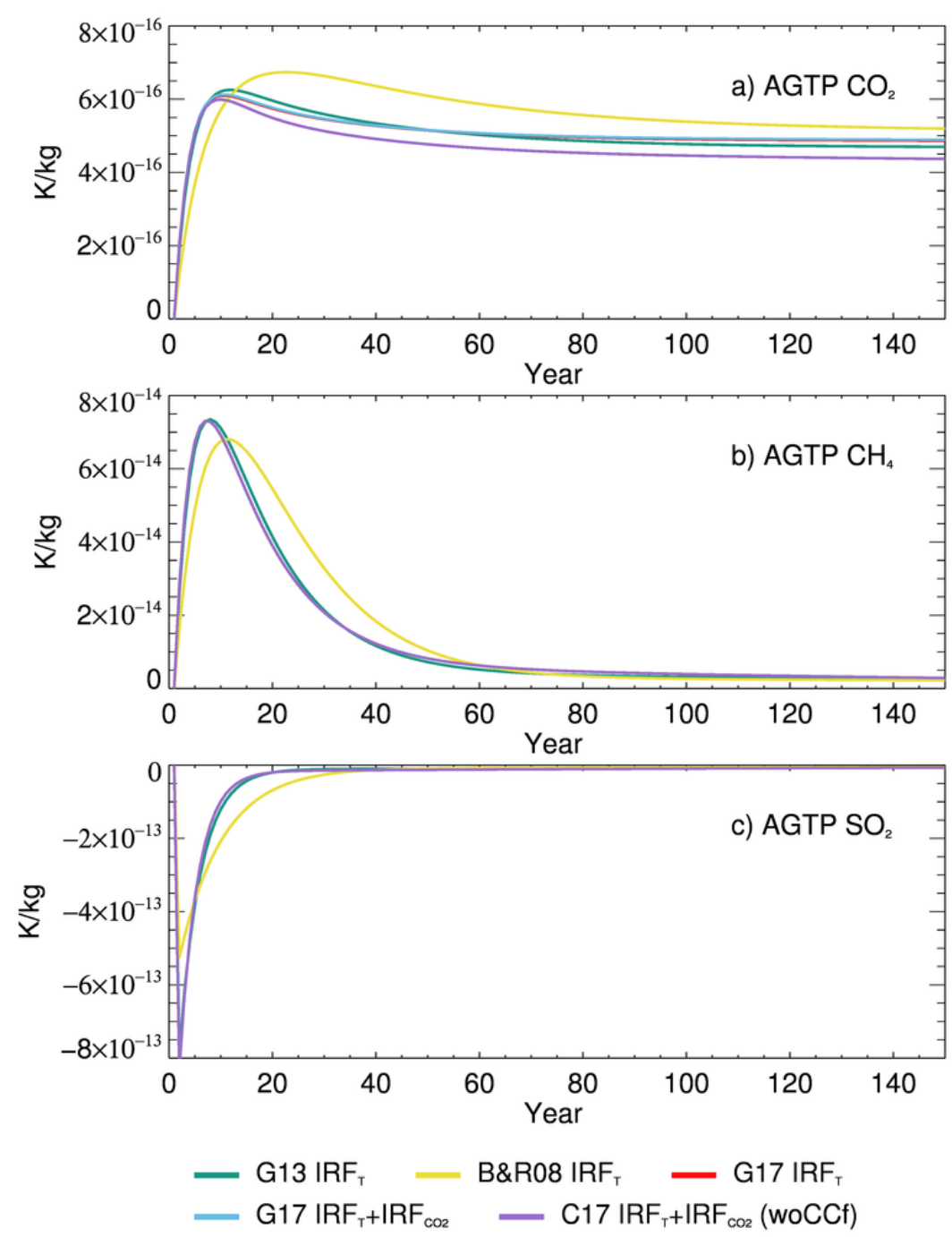

Figure S1: AGTP(t) for $\mathrm{CO}_{2}, \mathrm{CH}_{4}$ and $\mathrm{SO}_{2}$ as calculated using different combinations of climate response and carbon dioxide impulse response functions: B\&R08 (Boucher \& Reddy, 2008), G13 (Geoffroy et al., 2013) and G17 (Gasser et al., 2017) (all with the Joos et al. (2013) $\mathrm{CO}_{2}$ IRF), and G17 with corresponding $\mathrm{CO}_{2}$ IRFs with and without the carbon-climate feedback included.

Table S1: GTPs for methane using different combinations of climate response and $\mathrm{CO}_{2}$ IRFs.

\begin{tabular}{lccc}
\hline & \multicolumn{3}{c}{ GTP of methane } \\
\hline Time horizon & 10 & 20 & 100 \\
\hline AR5 & 100 & 64 & 4 \\
B\&R08 IRF & 114 & 77 & 5 \\
G13 IRF & 109 & 65 & 6 \\
G17 IRF & 108 & 63 & 8 \\
G17 IRF $_{\mathrm{T}}+$ IRF $_{\mathrm{CO} 2}$ & 108 & 63 & 8 \\
G17 IRFT + IRFCO2 (noCCf) & 110 & 67 & 9 \\
\hline
\end{tabular}


a) G13 IRF

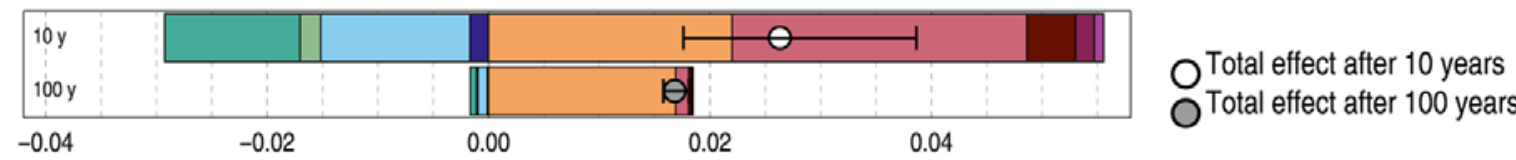

b) B\&R08 IRF
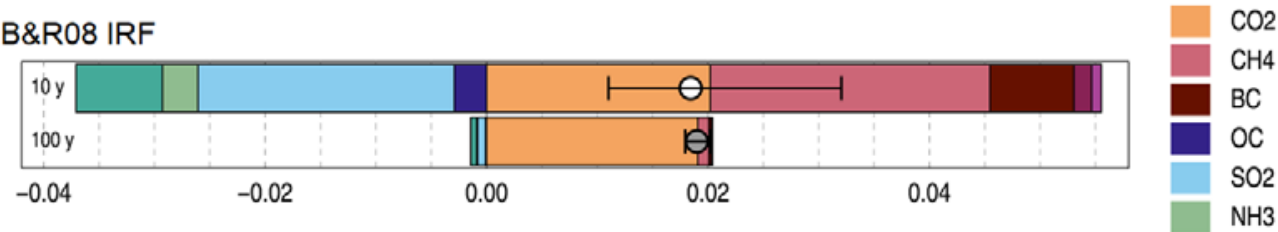

c) G17 IRF

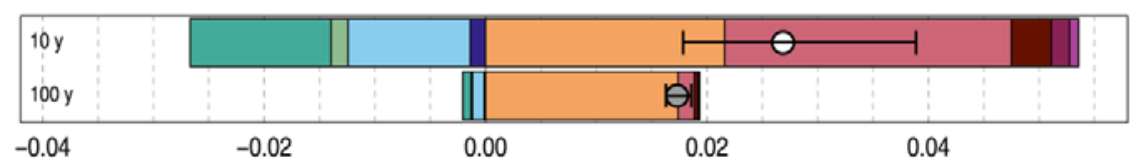

NOx

$\mathrm{CO}$

VOC

Figure S2: Global-mean surface temperature impact 10 and 100 years after one year of global present-day (i.e., year 2014) emissions of SLCFs and $\mathrm{CO}_{2}$, calculated using different combinations of climate response. 

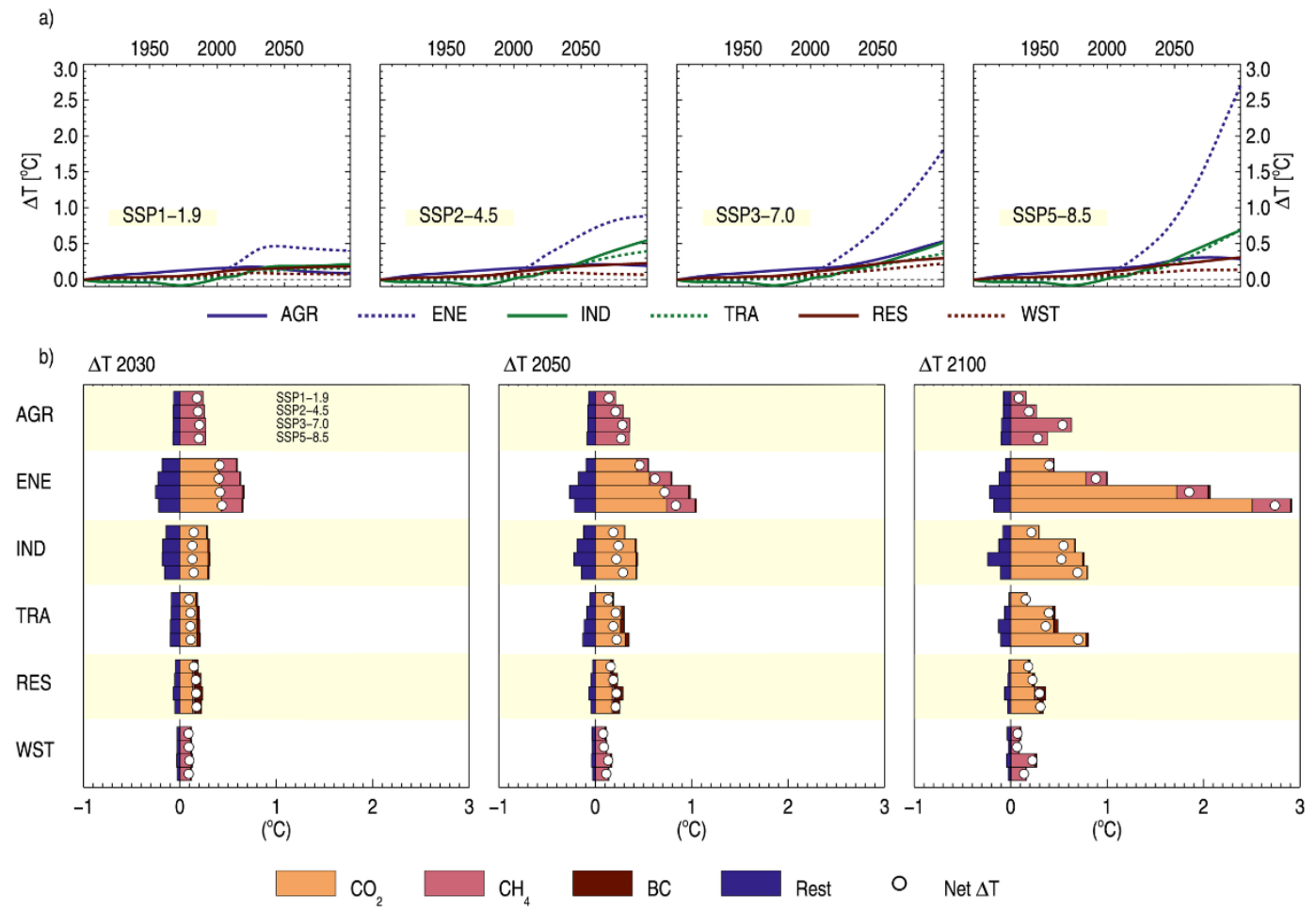

Figure S3: Global mean temperature response to historical emissions and future SSP pathways: a) Net (i.e., sum over all species and regions) response over the period 1900 to 2100 for each sector and scenario and b) net response in 2030, 2050 and 2100 to emissions in six of our seven sectors (excluding shipping, which remains much smaller than the rest), broken down by contributions from $\mathrm{CO}_{2}, \mathrm{BC}$, methane and the sum of $\mathrm{SO}_{2}, \mathrm{OC}, \mathrm{NH}_{3}$ and ozone precursors ("Rest”). 


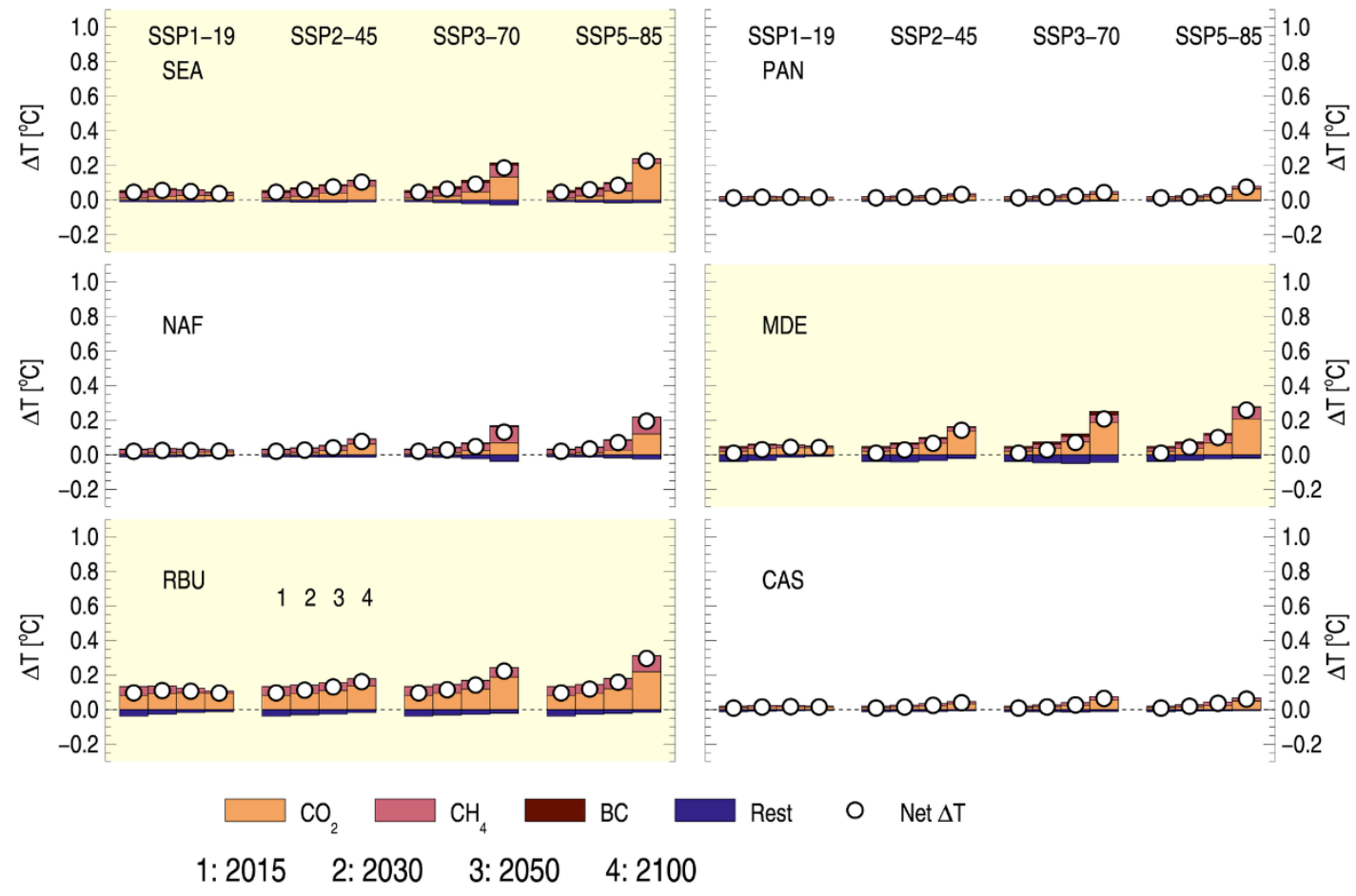

Figure S4: Global mean temperature response to historical emissions and future SSP pathways: Net response in 2015, 2030, 2050 and 2100 to emissions in six regions broken down by contributions from $\mathrm{CO}_{2}, \mathrm{BC}$, methane and the sum of $\mathrm{SO}_{2}, \mathrm{OC}, \mathrm{NH}_{3}$ and ozone precursors (i.e., "Rest”).

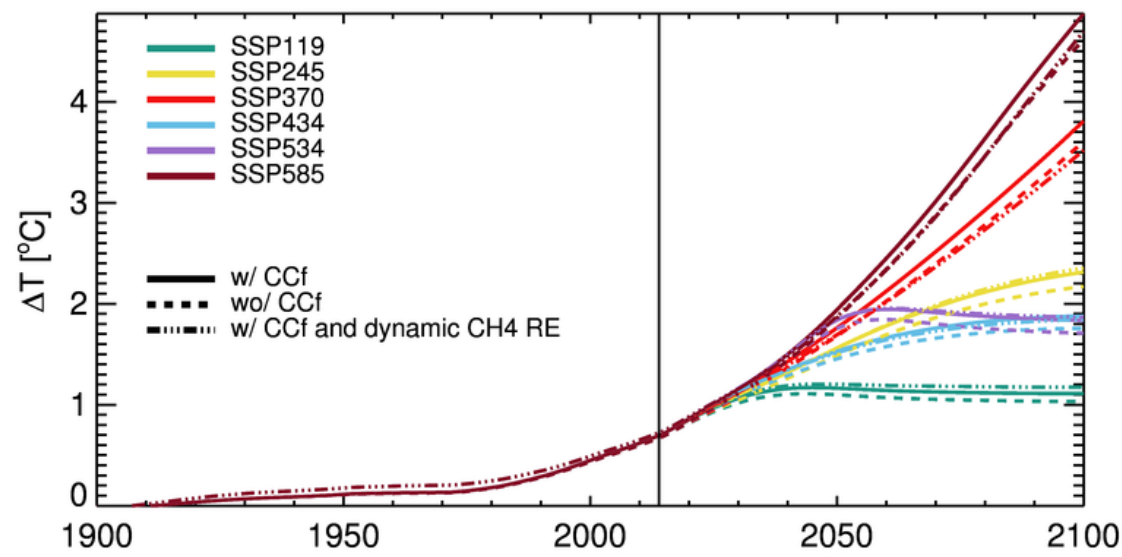

Figure S5: Impact of including carbon-climate feedback and dynamical methane radiative efficiency in the AGTP calculation on global mean total net temperature response to total emissions (i.e. sum of our sectors and regions) under 6 of the SSP-RCPs. 


\section{References:}

Boucher O. \& Reddy M. S. Climate trade-off between black carbon and carbon dioxide emissions, Energy Policy. 36(1), 193-200, https://doi.org/10.1016/j.enpol.2007.08.039, 2008.

Etminan M., Myhre G., Highwood E. J., et al. Radiative forcing of carbon dioxide, methane, and nitrous oxide: A significant revision of the methane radiative forcing, Geophysical Research Letters. 43(24), 12,614-612,623, 10.1002/2016gl071930, 2016.

Gasser T., Peters G. P., Fuglestvedt J. S., et al. Accounting for the climate-carbon feedback in emission metrics, Earth Syst. Dynam. 8(2), 235-253, 10.5194/esd-8-235-2017, 2017.

Geoffroy O., Saint-Martin D., Olivié D. J. L., et al. Transient Climate Response in a Two-Layer Energy-Balance Model. Part I: Analytical Solution and Parameter Calibration Using CMIP5 AOGCM Experiments, Journal of Climate. 26(6), 1841-1857, 10.1175/jcli-d-12-00195.1, 2013.

Joos F., Roth R., Fuglestvedt J. S., et al. Carbon dioxide and climate impulse response functions for the computation of greenhouse gas metrics: a multi-model analysis, Atmos. Chem. Phys. 13(5), 2793-2825, 10.5194/acp-13-2793-2013, 2013.

Myhre G., Shindell D., Brèon F.-M., et al. Anthropogenic and natural radiative forcing. In: Climate Change 2013: The Physical Science Basis. Contribution of Working Group I to the Fifth Assessment Report of the Intergovernmental Panel on Climate Change [Stocker, T.F., D., Qin, G.-K. Plattner, M. Tignor, S.K. Allen, J. Boschung, A. Nauels, Y. Xia, V. Bex and P.M. Midgley (eds). Cambridge University Press, Cambridge, United Kingdom and New York, NY, USA 2013. 